\title{
BIM, STRUCTURAL ANALYSIS AND COMMUNICATION USING COMMON DATA ENVIRONMENT (CDE) IN THE FIELD OF WATER MANAGEMENT
}

\author{
P. Vlasák ${ }^{1}$, B. Čerbák ${ }^{2}$ \\ ${ }^{1}$ AQUA PROCON s.r.o., Palackého tř. 12, 61200 Brno - pavel.vlasak@ aquaprocon.cz \\ ${ }^{2}$ AQUA PROCON s.r.o., Palackého tř. 12,612 00 Brno - borek.cerbak@aquaprocon.cz
}

KEY WORDS: BIM, CDE, IFC, Structural Analysis, Water Management

\section{ABSTRACT:}

Presentation consists of three parts, which are interconnected:

1. BIM application for plants treatment and other complicated structures in the field of water management

2. Statics of water management structures in the BIM environment

3. Application of Common Data Environment (CDE) for water management

Two areas - statics and water management technology - are crucial for water management structures. Speaking of statics, we mean the statics of reinforced concrete structures. In our company AQUA PROCON s.r.o. we deal with this area comprehensively, ie. from the initial design in the BIM architectural and construction software, through transferring a load-bearing model to BIM software for 3D reinforcement modelling to evaluating model in static design software. All communication is held in Common Data Environment (CDE). Within this environment, a three-way communication is carried out by the designer, contractor and contracting authority. Part of our performance is also above-standard support for reinforced concrete contractors. We provide models of reinforced concrete structures in LOD 400. The use of Common Data Environment (CDE) does not concern only statics, but also the work of all other professions and project participants. Our activities and workflows are based on the philosophy of OPENBIM and IFC.

\section{MANUSCRIPT}

\subsection{Data collection}

We use modern methods of data acquisition, such as laser scanning, digital photogrammetry and Unmanned Aircraft Systems (UAS), in the area of spatial data collection and preparation of data for our design activities within water management structures. We use this data to create BIM models of water management objects and to create a digital terrain model of an existing and proposed state. In recent years, geology has become a part of digital terrain model in our company.

\subsection{Company workflow}

Two areas - statics and water management technology - are crucial for water management structures. When speaking of statics, we mean the statics of reinforced concrete structures. In our company AQUA PROCON s.r.o. we deal with this area comprehensively, ie. from the initial design in the BIM architectural and construction software, through transferring a load-bearing model to BIM software for 3D reinforcement modelling to evaluating model in static design software. All communication is held in Common Data Environment (CDE). Within this environment, a three-way communication is carried out by the designer, contractor and contracting authority. Part of our performance is also above-standard support for reinforced concrete contractors. At random let's mention e.g. access to the model and documentation throughout the construction in the Common Data Environment (CDE), or breakdown of the model according to working widths, which supported optimal organization of work on the construction site, up to digital outputs for bending machines. We provide models of reinforced concrete structures in LOD 400. These models include the realization shape of concrete structures including bar and mesh reinforcement, fixtures, expansion joints, etc. The use of Common Data Environment (CDE) does not concern only statics, but also the work of all other professions and project participants. Our activities and workflows are based on the philosophy of OPENBIM and IFC.

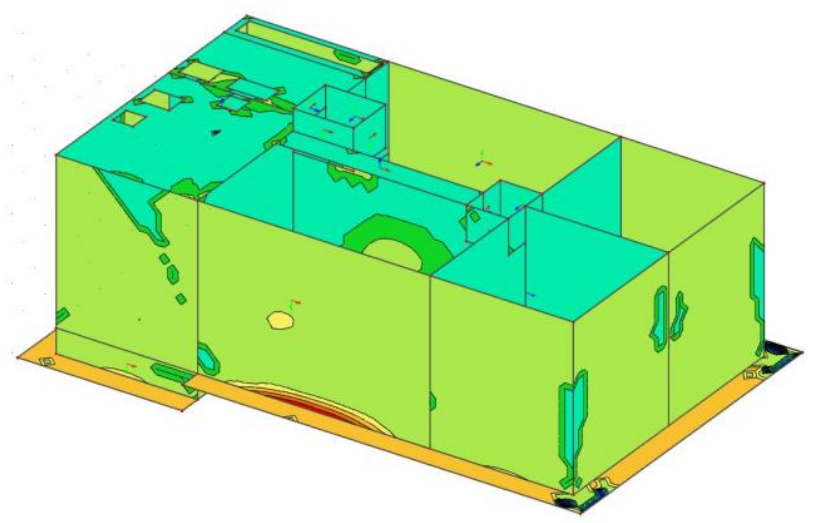

Figure 1. Necessary reinforcement areas 


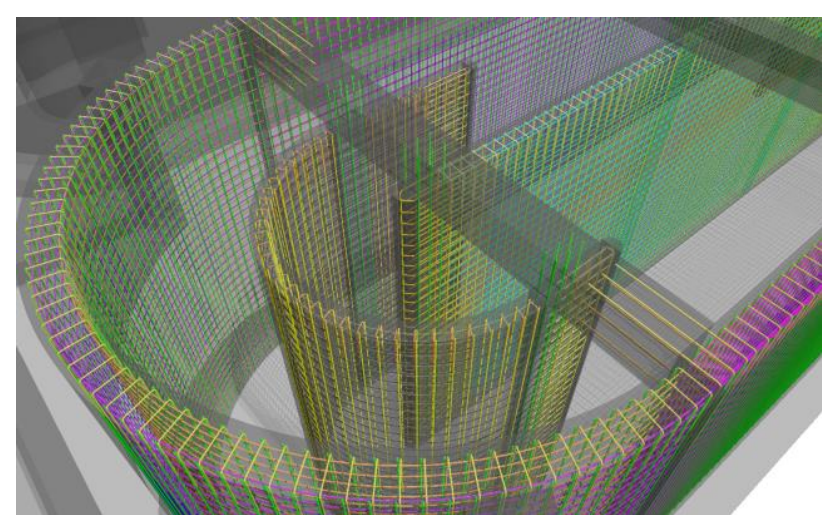

Figure 2. 3D reinforcement

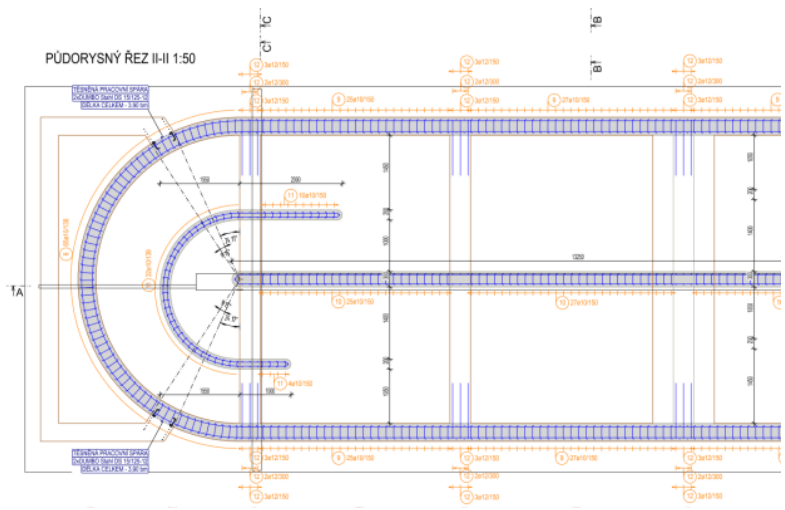

Figure 3. Reinforcement drawings

\subsection{Common Data Environment (CDE) and IFC}

In selecting a Common Data Environment (CDE), in addition to supporting reliable data and project information exchange, displaying individual tasks, roles of individual team members and enabling and working offline, two functionalities played an important role - the ability to display an unlimited number of reference models in one coordination view and the ability to use the CDE environment itself to display models primarily in IFC format in Microsoft HoloLens glasses supporting mixed reality, the technologically highest level of reality currently available on the market.

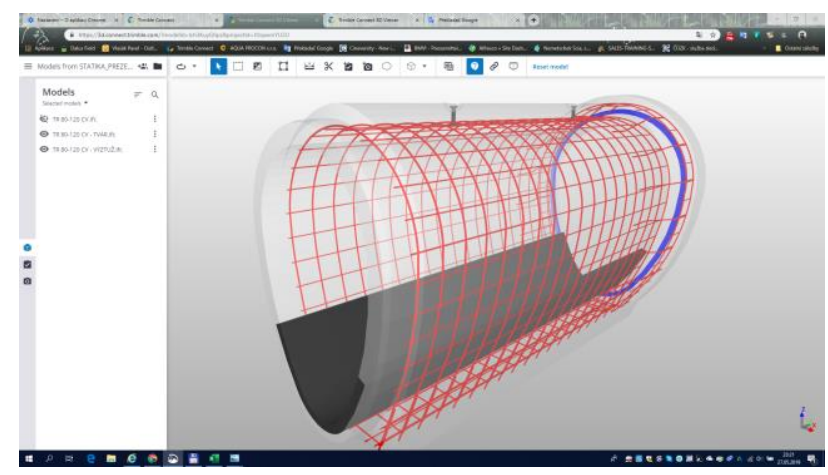

Figure 4. 3D reinforcement in CDE

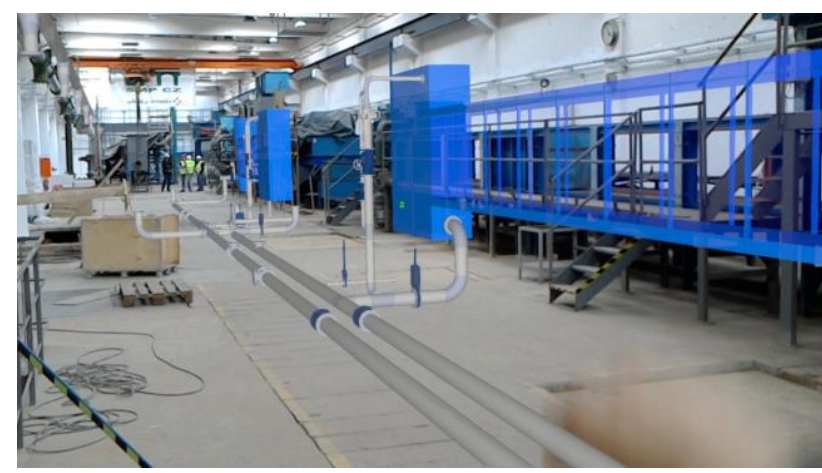

Figure 5. Mixed reality in Microsoft HoloLens

\section{LIST OF ABBREVIATIONS:}

\subsection{OPENBIM / IFC}

The OpenBIM initiative assumes that the only possible way to truly effective cooperation is based on open access to information. In relation to software tools, this means that the data format through which programs communicate (share a project) must also be open. The basic standard for OpenBIM communication is the IFC data format, which is being developed under the auspices of buildingSMART ${ }^{\circledR}$ International. Besides other things, the quality of the IFC standard is reflected in its adoption as an ISO standard. A comprehensive summary of OpenBIM information can be found at www.OpenBIM.cz.

\subsection{COMMON DATA ENVIRONMENT (CDE)}

This is a central information repository that can be accessed by all project participants. It is a collaborative environment everyone can use to coordinate information with supply chain members, as outlined in PAS1192 and BS1192. PAS 1192: 2 provides guidance on how CDE should be implemented. These standards are currently being replaced by the ISO 19650 Standard, which was developed based on the well-established British Standard BS 1192 and the publicly available specification PAS 1192-2.

\subsection{REFERENCES:}

http://www.aquaprocon.cz/ https://www.buildingsmart.org/ https://trimbleconnect.cz/ https://bimforum.org/lod/ https://www.sfdi.cz/bim-informacni-modelovani-staveb/ http://www.cegra.cz/bim/openbim-ifc/ https://www.iso.org/obp/ui/\#search/std/19650 